\title{
A arte de Rei Kawakubo: diálogos entre moda e arte no universo da Comme des Garçons
}

\author{
The art of Rei Kawakubo: dialogues between fashion and art \\ in the universe of Comme des Garçons
}

por Isadora Ferraz Rodrigues e Cristiane Ferreira Mesquita

\section{RESUMO}

A presente pesquisa investiga os diálogos entre arte e moda através da trajetória da marca Comme des Carçons e de sua criadora, Rei Kawakubo, analisando aproximações e trocas entre essas duas linguagens. Através de uma revisão bibliográfica e iconográfica, evidenciam-se trocas entre moda e arte estabelecidas pela Comme des Garçons através de sua filosofia e do constante envolvimento de artistas que atuam como colaboradores na produção visual e conceitual da marca. A partir dessa investigação, conclui-se que algumas das relações estabelecidas entre arte e moda enriquecem e criam novas perspectivas em ambas as áreas. É com esse olhar que Rei Kawakubo estabelece sua marca como uma das mais significativas da contemporaneidade.

Palavras-chave Moda; Arte; Comme des Garçons

\section{ABSTRACT}

Moda, Arte, Comme des GarçonsThe present article investigates the dialogues between art and fashion trough the history of the brand Comme des Garçons and its creator, Rei Kawakubo, analyzing encounters and exchanges between these two languages. A bibliographic and iconographic research show that such exchanges between fashion and art established by Comme des Garcons are evident not only through its philosophy, but also though the constant involvement of artists, who work as collaborators in the entire visual and conceptual production of the brand. From this investigation, it was possible to conclude that the relations between art and fashion enrich and create new opportunities in both areas. With this view Rei Kawakubo establishes her brand as one of the most significant in contemporary fashion.

Keywords Fashion; Art; Comme des Garçons 


\section{Introdução}

Observando o percurso histórico da marca Comme de Garçons, nota-se que em inúmeros momentos estabeleceram-se uma série de colaborações entre a marca e diversos artistas. Uma breve investigação sobre arte e moda, a partir dessas colaborações e trocas, é o principal objetivo dessa pesquisa.

A partir das vanguardas do século XX, podemos considerar que a arte passa a ter outra função que não somente a representação: esse campo passa a questionar 0 mundo em que estamos inseridos e até o próprio conceito de arte. Da mesma forma que os questionamentos feitos pela arte desestabilizam e convidam a pensar a moda de forma não convencional, podemos considerar que as criações de Rei Kawakubo levantam questões acerca de convenções e regras próprias da moda e nos apresentam novas formas de vestir.

Criada em 1973, em Tóquio, a marca ganhou visibilidade internacional em 1981, quando desfilou sua primeira coleção em Paris. Diante de uma proposta de moda completamente diferente daquela que o mundo ocidental estava acostumado a ver na época, as reações do público e da crítica variavam entre o choque e a admiração.

Rei Kawakubo sempre se preocupou em criar uma identidade forte para a Comme des Garçons. Sendo assim, a estilista se envolve não só na criação das roupas, mas em todos os outros aspectos que abrangem a marca. E a aproximação desta última com a arte pode ser vista não somente nas roupas, mas em grande parte de sua produção visual, que envolve catálogos, revistas e convites. Muito do que é produzido mostra uma grande preocupação em ir além dos padrões estabelecidos e provocar reflexões.

Formada em artes e literatura, Rei Kawakubo sempre se manteve próxima da arte, tendo sempre trabalhado ao lado de artistas, fotógrafos e arquitetos. Tais profissionais colaboram com a marca constantemente, participando ou criando suas campanhas publicitárias, expondo suas obras nas lojas e desenvolvendo imagens que serão usadas na comunicação visual.

A Comme des Garçons criou uma linguagem própria, provocando e desafiando convenções, andando lado a lado com a arte, criando não apenas roupas, mas toda uma forma de pensar a moda.

\section{Rei Kawakubo: origem e trajetória}

Rei Kawakubo nasceu em Tóquio, no ano de 1942. Na época em que começou a frequentar a escola, o cenário no país era de uma economia e sistema político devastados pela Segunda Guerra Mundial. Porém, alguns anos depois, na época de sua formatura, o país já se encontrava em uma situação mais privilegiada. 


\section{A arte de Rei Kawakubo: diálogos entre moda e arte no universo da Comme des Garçons}

0 desenvolvimento do Japão, nos anos subsequentes, gerou diversas oportunidades para os membros de uma geração. 0 sucesso econômico da nação permitiu olhar o mundo de uma forma mais objetiva e fazer uma contribuição criativa própria, afirmando sua identidade como nação e recebendo reconhecimento do mundo ocidental. Como aponta Sudjic (1990), nessa época surgiram inúmeras pessoas que se tornaram decisivas na transformação da percepção que o mundo tinha do Japão:

Indivíduos notáveis e talentosos, como os arquitetos Tadao Ando e Arata Isozaki, o designer Shiro Kuramata e os três designers de moda de Tóquio, Rei Kawakubo, Yohji Yamamoto e Issey Miyake, entre outros artistas, escritores e diretores de cinema se tornaram proeminentes nesse período. Eles tiveram um papel tão importante quanto de engenheiros, industriais e banqueiros no estabelecimento de uma reputação internacional do país (SUDJIC, 1990, p. 40).

Ao deixar a escola, ela passou a cursar Belas Artes e literatura na Universidade de Keio, fazendo parte de seus estudos as artes japonesa e ocidental. Kawakubo se graduou em 1964 e passou a trabalhar no departamento de propaganda da Asashi Kasei, uma grande empresa química e maior produtora de fibras acrílicas do Japão. Nesse momento, ela não tinha em mente seguir uma carreira como designer, porém seu trabalho na empresa permitiu que conhecesse pessoas envolvidas com a moda e que aprendesse mais sobre a área.

Após sua saída da Asahi, Kawakubo passou a trabalhar como stylist ${ }^{2}$ freelancer, o que representava um avanço, já que essa era uma carreira rara e incomum na sociedade japonesa de 1967. Por ter dificuldades em encontrar o tipo de roupa que desejava usar em seus stylings, ela passou a desenhar roupas que atendessem aos seus anseios. Em 1969, Kawakubo já usava o nome Comme des Garçons para suas criações, mas a marca só foi estabelecida formalmente como uma companhia em 1973. Assim, a decisão de se tornar uma designer aconteceu naturalmente, apesar de nunca ter recebido treinamento formal em moda.

A designer começou a vender suas criações comercialmente no início da década de 1970. Algumas de suas primeiras peças não chegaram ao público sob o nome Comme Des Garçons. No início, as roupas eram vendidas em uma loja experimental chamada de Belle Boudoir, que atraía pessoas interessadas em moda em Tóquio e deu a vários jovens designers seu primeiro espaço de exposição. Nessa época, o mundo não percebia o Japão como um lugar onde se poderia encontrar um design de moda interessante e inovador, porém estilistas como Kenzo Takada e Issey Miyake começavam a chamar atenção do ocidente.

1 Stylist é palavra inglesa para referir-se ao profissional que define a imagem de um desfile, catálogo ou editorial de moda. Sugere e ajuda a selecionar modelos, faz a edição das roupas a serem usadas e ajuda a determinar a maquiagem e o cabelo a serem adotados; nos desfiles, interfere na atitude das modelos e opina sobre cenário e trilha sonora (SABIN0, 2007, p.563) 
No ano de 1976, Rei Kawakubo abriu sua primeira loja em Tóquio, no bairro de Aoyama. Entre 1975 e 1796, ela apresentou sua primeira coleção feminina e iniciou uma colaboração com o arquiteto Takao Kawasaki para desenvolver uma identidade para suas lojas. A experiência de Kawakubo como stylist serviu como base para que a marca transmitisse uma imagem coerente e que deveria permear todos os seus aspectos. Em 1978, teve início sua linha masculina, a Homme. Em pouco tempo, ela criou outras linhas, entre elas a Tricot, a Robe de Chambre, em 1981, e a Noir, em 1987.

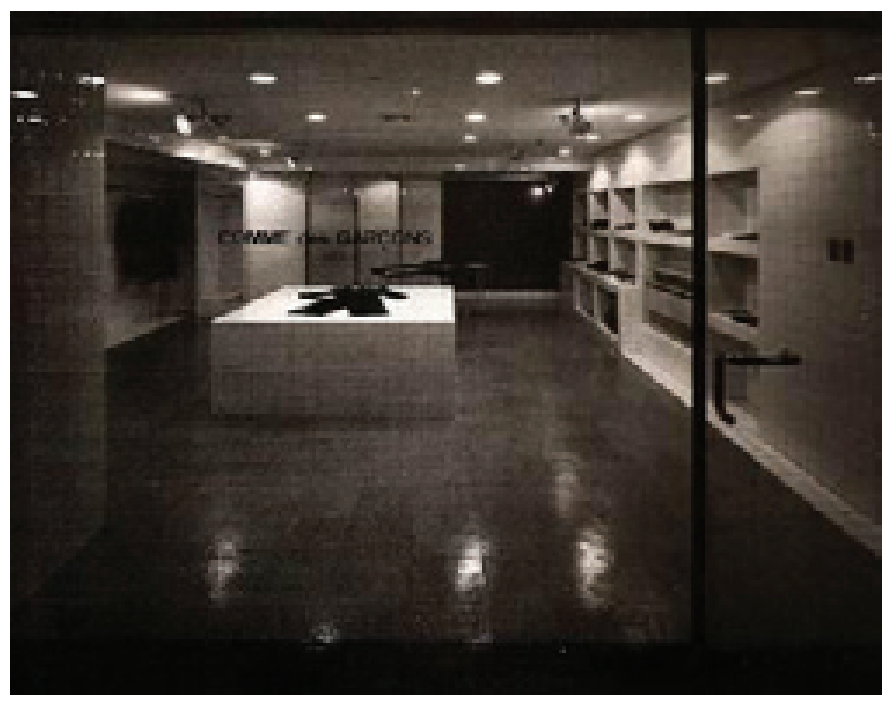

Figura 1 - A loja de Aoyama foi planejada juntamente com o arquiteto Takao Kawasaki para ter um interior de aspecto hospitalar. Fonte: Rei Kawakubo and Comme des Garçons, 1990.

Na medida em que a Comme des Garçons se tornava bem-sucedida, Kawakubo começou a assinar acordos com franquias que operariam sob o nome da marca. No começo da década de 1980, com 80 empregados no escritório de Tóquio, a Comme des Garçons já vendia US\$ 30 milhões por ano, em 150 lojas.

Depois do grande sucesso comercial ao final da década de 1970, exibiu ,em 1981, sua primeira coleção em Paris. Desfilar uma coleção na capital francesa Ihe custou muito dinheiro, porém compradores ocidentais e a mídia não poderiam viajar à Tóquio para ver suas coleções, e Kawakubo sabia que se quisesse ser reconhecida como uma designer internacional, teria que se apresentar em Paris.

A crítica ficou dividida a respeito de seu desfile na ocasião de sua estreia. Rei Kawakubo obteve respostas positivas de alguns jornalistas que a consideraram bem-sucedida em sua empreitada. Outros demonstraram dúvidas a respeito de suas silhuetas, consideradas sem forma e sua predileção pelo monocromático, julgado fúnebre por alguns. Após seu primeiro desfile em Paris, Rei Kawakubo se firmou rapidamente na cidade, tornando-se parte da Chambre Syndicale du Prêt-à-Porter, e em novembro de 1982 abriu sua primeira loja fora do Japão. Em 1988, Kawakubo 


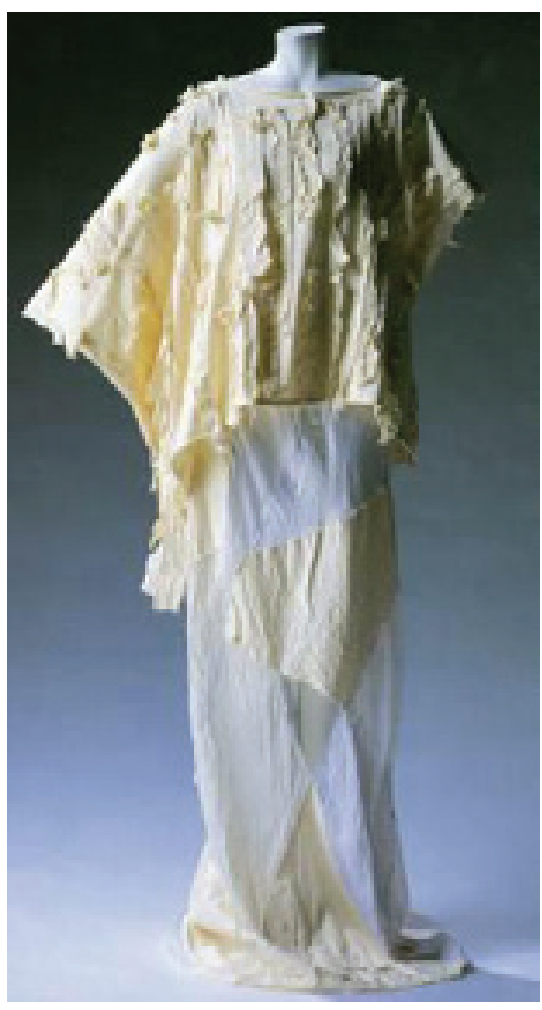

Figura 2 - Look da coleção de 1983, ano em que as coleções da Comme de Garçons ficaram caracterizadas por sua desconstrução. Fonte: Fashion, 2006.

introduziu a Comme des Garçons Shirt, uma linha de camisas produzidas na França e vendidas a um preço acessível.

Apesar de seu sucesso parecer repentino pelo impacto de seu primeiro desfile em Paris, Kawakubo já desenhava roupas há 12 anos no Japão. No início de sua carreira, seus desenhos eram considerados comerciais, porém o que foi visto na coleção de 1981 não lembrava em nada a moda ocidental. Para Sudjic (1990) suas roupas, de formas nunca antes vistas, eram tidas como um ataque às ideias ocidentais de moda.

No contexto da moda contemporânea, a Comme des Garçons é uma marca financeiramente bemestabelecida e independente. Apesar de todo o sucesso e anos de trajetória, Rei Kawakubo ainda possui o poder de surpreender. Ao invés de permitir que seus entusiastas se tornem familiares com o seu trabalho, ela se reinventa, corre riscos e repensa suas próprias abordagens de uma coleção a outra (SUDJIC, 1990). Suas criações exploram peças monocromáticas - com as quais se tornou conhecida -, mas também as cores, experimentando formas e novas possibilidades do vestir.

Atualmente Rei Kawakubo ainda assume o papel de estilista da marca, juntamente com os designers Junya Watanabe e Tao Kurihara, que iniciaram suas carreiras como seus aprendizes e hoje em dia são responsáveis por suas próprias linhas dentro da Comme des Garçons.

\section{Comme des Garçons e o mercado}

Apesar das criações de Rei Kawakubo terem um caráter conceitual, elas conquistaram grande sucesso comercial no mercado internacional de moda. A Comme des Garçons tem um alcance global e mantém diversas lojas pelo mundo; entre elas a de Aoyama, bairro de Tóquio que concentra grandes marcas de moda, e a da Place vendôme em Paris.

Além de seus estabelecimentos convencionais, a Comme des Garçons mantém ainda suas Guerilla Stores. 0 primeiro estabelecimento nesses moldes foi aberto 
em Berlim em 2004. As Guerilla são simples, localizam-se em bairros não usuais, são levantadas com um mínimo de investimento e ficam abertas por apenas um ano. Lojas com o conceito Guerilla foram abertas em diversas cidades do mundo.

Em 2004, foi inaugurado o Dover Street Market, concebido por Rei Kawakubo. A loja abriga em seus diversos andares não só as linhas da Comme des Carçons, mas também produtos de outros designers escolhidos por ela. Cada designer é convidado a criar seu espaço à sua própria maneira, além de desenvolverem peças especialmente para serem comercializadas no local. No website do Dover Street Market², Rei Kawakubo explica sua intenção: "Eu quero criar um tipo de mercado onde diversos criadores de diversas áreas se unam e se encontrem em uma atmosfera contínua de 'belo caos': a mistura e união de almas semelhantes que dividem um forte ponto de vista pessoal".

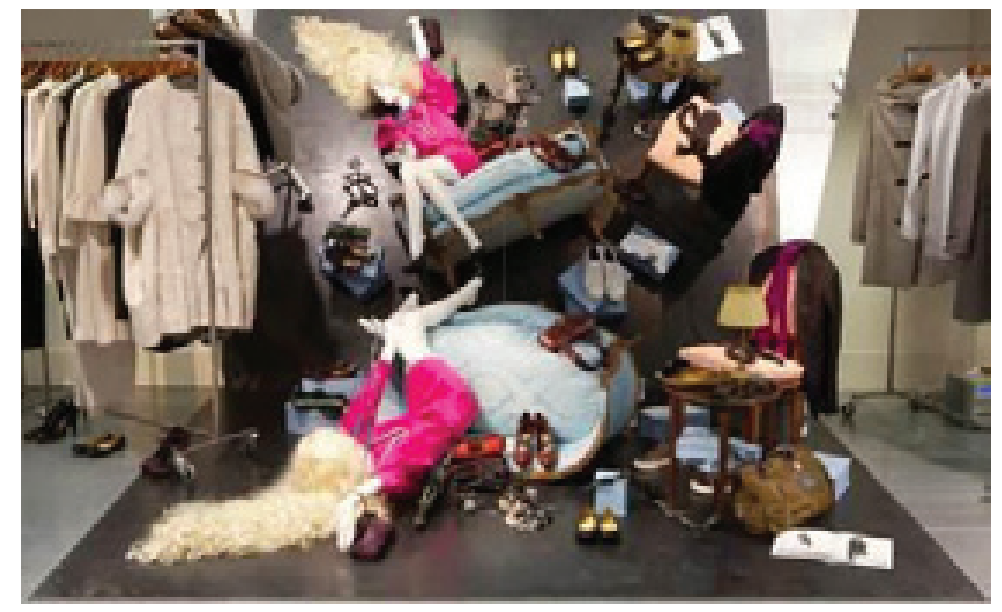

Figura 3 - Instalação do estilista Alber Elbaz na Dover Street Market. Fonte: 〈http://www.doverstreetmarket.com〉. Acesso em 20 Fev. 2011.

Além de sua linha principal, a marca mantém ainda outras 14 linhas que incluem a Comme Des Garçons Homme, Comme Des Garçons Tricot, Comme Des Garçons Play, Comme Des Garçons Shirt e Comme des Garçons Noir.

A designer insiste na ideia de que suas roupas devem ser vendidas em ambientes controlados, onde tudo é pensado, desde o espaço físico da loja até a forma como os vendedores se aproximam do cliente; do visual da loja ao corte das roupas tudo se sustenta em uma mesma ideia.

2 Dover Street Market. Disponível em <http://www.doverstreetmarket.com/about/>. Acesso em 20 Fev. 2011. 


\section{Alguns dos princípios que regem a criação da Comme des Garçons}

Rei Kawakubo é presidente de sua própria companhia e detém toda a responsabilidade não só da direção criativa, mas também da parte administrativa empresa. Seu trabalho é parte de uma estratégia que visa garantir o sucesso comercial a fim de manter sua liberdade criativa. Apesar de manter controle sobre sua organização, ela escolheu um nome para sua marca, que não o seu próprio, pois desde 0 início sentiu a necessidade de uma identidade para a empresa que não dependesse de sua presença. A escolha desse nome apresenta ainda outras razões, como demonstra Grand (1998):

Esse nome, que soa francês como um grupo de rock ou uma companhia de bailarinos, reivindica desde sua origem uma existência internacional e uma crença no trabalho coletivo: recusar-se a usar o nome do criador é distanciar-se do estatuto do artista que mantém relações ambíguas com a moda, que é indústria, ganha pão, negócio. Seu tempo é o presente ou o futuro imediato, não a eternidade (GRAND, 1998, p.5).

Em busca da criação de uma identidade forte para a marca, Rei Kawakubo se envolve diretamente em todos os seus aspectos. Não se limita somente às roupas, a identidade da Comme Des Garçons pode ser vista também em tudo o que ela produz: desde toda a sua produção gráfica até mobília, passando por catálogos e a arquitetura das lojas.

A criadora possui uma abordagem própria com relação à moda e afirma que "gosta de começar do zero" (SUDJIC, 1990), reexaminando não somente a aparência das roupas, mas também sua construção. Sua maneira de criar se aproxima daquela dos arquitetos modernistas como Le Corbusier', a quem admira: é clara a influencia de seu purismo na forma como a designer lida com os princípios de textura, forma e cor.

Desde a primeira apresentação em Paris, as criações de Rei Kawakubo mostravam silhuetas que diferiam muito da tradição ocidental, que procurava modelar o corpo feminino. Não partilhavam da lógica ocidental que girava em torno da ocultação e da exibição, nem tentavam trazer para o corpo formas preconcebidas. Ao invés disso, textura, sobreposição e a forma das roupas eram consideradas objetos de interesse por si só. As roupas femininas da Comme des Garçons tendiam a ser largas e amplas, e apesar de desafiarem a noção das roupas convencionais, isso não era feito de forma que contradissesse o corpo humano. Para Kawakubo, o design

3 Charles-Edouard Jeanneret-Gris, mais conhecido pelo pseudônimo Le Corbusier, foi um importante arquiteto, urbanista e pintor de origem Franco-Suíça. 1887-1965. Le Corbusier: architect biography. Disponível em: 〈http://architect.architecture.sk/le-corbusier-architect/le-corbusier-architect.php〉. Acesso em: 14 Mar. 2011. 
não diz respeito somente a revelar e acentuar a forma do corpo feminino, ele deve permitir a cada pessoa afirmar sua identidade. Segundo Sudjic (1990), a designer quer libertar as mulheres das formas convencionais do vestir. Apesar dessa filosofia, ela nunca se considerou uma feminista; seu trabalho diz respeito somente à liberdade de criação.

Seu famoso Lace Sweater, um suéter propositalmente cheio de buracos, obtidos a partir do afrouxamento de parafusos na máquina, pode ser considerado como um questionamento da perfeição atingida pela máquina. Para Rei Kawakubo, é o toque humano e a imperfeição que dão à roupa seu caráter distinto como explica Grand:

o famoso pulôver preto furado, muitas vezes considerado a bandeira negra da anarquia, seria, melhor dizendo, o emblema de uma elegância diferente: aquela, confiante, dos bailarinos em exercício, das fotos de Marilyn usando um pulôver, de Jack Kerouac na estrada, de Pollock em seu Ateliê, do free jazz, do Living Theatre, dos filmes de Jean-Luc Godard, daqueles que soltam os parafusos muito apertados das máquinas de tricotar ideias feitas (GRAND, 1998, p.9).

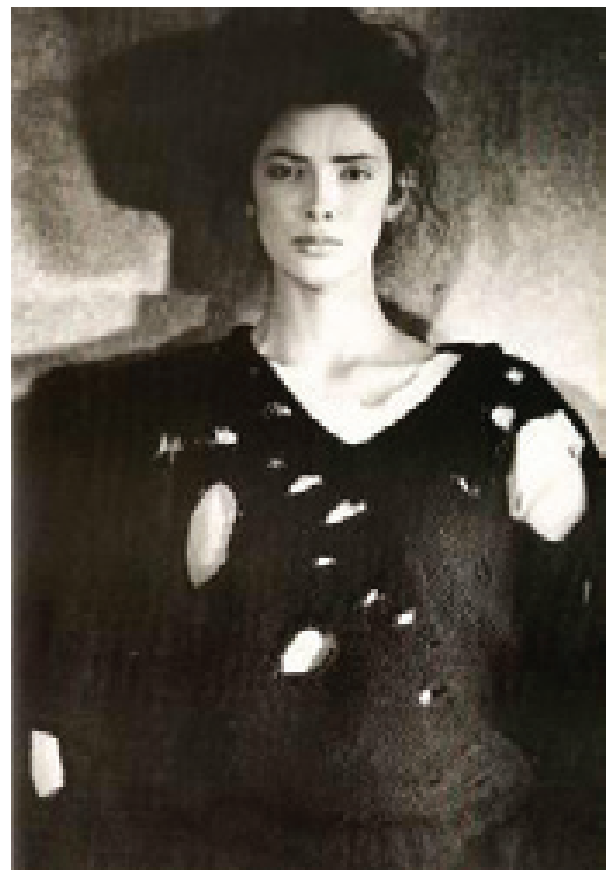

Figura 4 - 0 famoso Lace Sweater fotografado por Peter Lindbergh para o catálogo de Outono-Inverno 82/83. Fonte: Comme des Garçons, 2000.

As criações de moda masculina demonstram as mesmas preocupações. Camisas de colarinhos duplos e botões de tamanhos diferentes entre si, mostram uma parcela da capacidade da estilista em repensar e reinventar roupas comuns.

0 principal interesse de seu design é a forma das roupas. Suas criações parecem começar com um mínimo, sem qualquer decoração. No início de sua carreira, ao se privar das opções de cores e estampas, ela se certificou de seu foco na forma e da silhueta.

Kawakubo gosta de criar roupas que possam ser manipuladas pelo usuário. Por exemplo, uma jaqueta com forro que pode ser desabotoado para ser usada como suéter pode parecer não ter um propósito prático, mas a ideia de que isso é possível afeta a maneira como o usuário se sente. Outros exemplos podem ser vistos em uma camiseta com luvas integradas, além de uma jaqueta com lapela destacável que se transforma em lenço. A inclusão de elementos modificáveis numa roupa permite uma interferência do usuário, a qual tem um papel na definição da forma final da peça. 


\section{A arte de Rei Kawakubo: diálogos entre moda e arte no universo da Comme des Garçons}

\section{Moda e Arte}

A arte, por longo tempo, se dedicou a representar o mundo em que vivemos, duplicando suas imagens e espelhando a realidade. Preciosa (2005) afirma que, a partir do século XX, a arte passa a ter outra função que não somente a representação: ela começa a questionar o mundo em que estamos inseridos e até o próprio conceito de arte. A arte deixou de fazer uma imitação da realidade e passou a ter um papel na construção da realidade.

Diante desses questionamentos, percebe-se que arte é capaz de perturbar e desestabilizar o pensamento convencional. Ainda de acordo com Preciosa (2005), a arte nos dá pistas para pensar o mundo e nossa existência incluída nele. Incomoda nosso pensamento, forçando um exercício de sensibilidade e uma desautomatização de modos de pensar, sentir e agir.

A relação dos artistas com a moda se dá desde o início do século XX, sendo que os primeiros a utilizarem roupas como forma de arte foram os cubistas. Para Celant (1997), cortar e reorganizar formas, figuras, imagens e materiais, na superfície e no espaço, era um processo radical que mudou a maneira de perceber a realidade e construir uma nova existência. As primeiras concepções modernas de design, fotografia, arte gráfica, moda e cinema derivam do cubismo e de suas colagens. Seus cortes questionavam a ideia de que as coisas são absolutas. Em seguida, alguns anos após os cubistas, o futurismo foi o primeiro movimento a dramatizar a lógica de uma arte que corta e rompe, cruza e intercepta. Existia nos futuristas o desejo por uma transformação radical, uma "mudança de pele" e consequentemente da segunda pele, a roupa. A moda também foi bem explorada por diversos outros artistas e movimentos artísticos ao longo do tempo4.

Tratando-se de design de moda, nos cabe pensar os momentos em que este campo escapa das próprias convenções e regras para nos apresentar experimentações nas formas de vestir e de ser. A moda de vanguarda pode ser considerada aquela que, assim como a arte, resiste aos mecanismos e ideias pré-concebidas.

De acordo com Crane (1987), o termo avant-garde implica um grupo de artistas que tem forte comprometimento com valores estéticos e iconoclastas, rejeitando a cultura popular e o estilo de vida médio. Em geral, eles se opõem aos valores sociais dominantes e convenções artísticas estabelecidas. 0 mesmo termo pode-se aplicar a designers como Rei Kawakubo, que se rebelam contra os modos convencionais de viver e se relacionar determinados pela sociedade. Eles descobriram que é importante não limitar-se pela tradição, costume ou geografia e ser livre de qualquer influência na expressão de formas, cores e texturas. Rei Kawakubo

4 Surrealistas utilizaram a linguagem da moda com frequência em suas criações, como se pode ver na obra de Salvador Dalí e de Elza Schiaparelli. Diversos outros artistas exploraram as roupas como forma questionamento, entre eles Christo, Andy Warhol e Roy Lichtenstein e Louise Bourgeois. 
desafia não só o conformismo da sociedade japonesa, mas também as normas da socidade ocidental.

Como outras formas de design, podemos considerar que a moda tem questões próprias que a diferenciam da arte, do artesanato e do design industrial. Crane (1987) afirma que ela é uma forma de design tridimensional que incorpora elementos de todas essas áreas. Seu foco no corpo e no tecido, além do fato de ser desenhada para ser vendida e usada, a distingue da arte. A moda deve ser entendida em seus próprios termos, $e$ isso faz de suas interações com outros aspectos da arte e da cultura mais significativos. No entanto, esse campo se apropria, reconfigura e testa as fronteiras dessas definições.

\section{Comme des Garçons e a arte: diálogos e interseções}

\section{Rei Kawakubo no território da arte}

0 trabalho de Rei Kawakubo ganhou grande respeito não só no âmbito da moda, mas também na esfera da arte. Grande parte da produção da marca, desde sua criação, se tornou alvo do interesse de mostras e exposições ao redor do mundo. A Comme des Garçons e sua criadora são um dos principais exemplos de como a moda habita um espaço antes destinado à arte, deslocando a roupa da passarela para o museu, criando para ela novos significados e convidando o público a pensar a moda sob um viés que problematiza o próprio contexto e o universo no qual se insere. Citaremos alguns desses acontecimentos, que analisaram as relações e diálogos entre a criação de Rei Kawakubo e o campo da arte.

Em 1987, o New York Fashion Institute of Technology exibiu a exposição Three Women, que colocava frente a frente os trabalhos das estilistas Madeleine Vionnet ${ }^{5}$, da designer de sportswear Claire McCardell ${ }^{6}$ e Rei Kawakubo. Sudjic (1990) aponta que, assim como Vionnet e McCardell, Kawakubo não se prendeu a nenhum período específico; ela se deleitou com o choque do novo e se apossou de tecnologia avançada na criação de suas roupas, mas ainda sim criou com uma compreensão do papel histórico da moda.

No ano de 1996, aconteceu a Biennale di Firenze. Examinando a relação entre arte e moda no século XX, a exposição consistiu em várias exibições espalhadas por mu-

5 Madeleine Vionnet, estilista francesa. 1876-1975. Teve maior proeminência no período de 1920 a 1930. Disponível em: 〈http://www.vionnet.com/about/madeleine-vionnet〉. Acesso em: 17 fev. 2011.

6 Claire McCardell, estilista norte-americana. 1905-1958. Teve maior proeminência no período de 1940 a 1950. Disponível em: < http://www.fashionencyclopedia.com/Ma-Mu/Mccardell-Claire.html〉. Acesso em: 17 fev. 2011. 


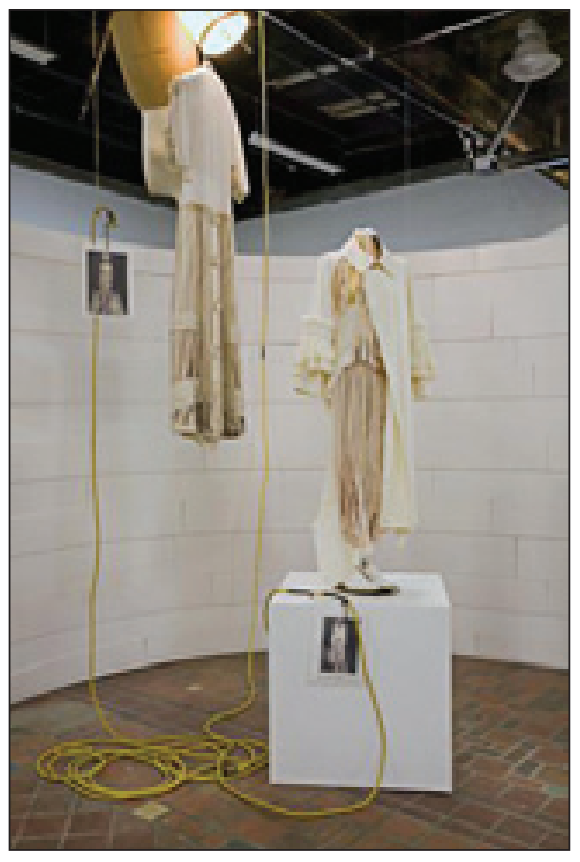

Figura 5 - Instalação realizada na exposição ReFusing Fashion. Fonte: <http://www.mocadetroit.org/exhibitions/ comme.html> Acesso em 11/03/2011.

seus e locais históricos da cidade de Florença. Para o evento foram construídos pavilhões projetados pelo arquiteto Arata Isozaki. Cada espaço abrigava uma instalação criada a partir da colaboração entre um artista e um estilista’ e, entre eles, estava a parceria entre Oliver Herring e Rei Kawakubo. Herring é um artista nascido na Alemanha em 1964, que, atualmente, vive e trabalha no Brooklyn, bairro da cidade de Nova York. Entre seus primeiros trabalhos destacam-se esculturas tricotadas com um material denominado Mylar, um filme plástico transparente feito de poliéster. A partir dessa técnica ele esculpia figuras humanas, roupas e mobília. Suas esculturas, que evocavam introspecção, mortalidade e memória, constituíam uma homenagem a seu amigo Ethyl Eichelberger, um artista performático que cometeu suicídio em 1991. Celant (1997) traz uma perspectiva sobre a colaboração de Kawakubo e Herring, afirmando que o objetivo desse trabalho era discutir 0 vazio e a imaterialidade. Através da construção de um espaço, a dupla procurou mostrar a cristalização do imaterial. Os materiais utilizados, como o Mylar e a musselina, movimentam-se na esfera do incorpóreo, devido à sua leveza e transparência. As palavras do curador narram alguns desdobramentos dos sentidos do trabalho:

Quer seja uma figura tecida ou uma paisagem, o imperativo aqui é a ausência, a aceitação do vazio que é plenitude na medida em que é a manifestação de uma interioridade, a estrutura do vestido assim como o sentir e o ver. Em oposição ao peso da carne que continua infundida dentro da segunda pele, eles oferecem uma noção metafísica do vestir (CELANT, 1997, p.240).

Em 2001, ocorreu, na cidade de Antuérpia, na Bélgica, a Mode 2001, evento que ocupou quatro espaços na cidade entre 26 de maio e 07 de outubro. Entre esses locais estava o Former Royal Palace, que abrigou 2 Women. Essa mostra colocou lado a lado Coco Chanel$^{8}$ e Rei Kawakubo, pois, na visão do curador, ambas desafiaram

7 Os encontros e colaborações se deram entre Tonny Cragg e Karl Lagerfeld, Damien Hirst e Miuccia Prada, Mario Merz e Jil Sander, Roy Lichtenstein e Gianni Versace, Julian Schnabel e Azzedine Alaïa, Jenny Holzer e Helmut Lang, e por fim, Oliver Herring e Rei Kawakubo (CELANT, 1997, p.238).

8 Gabrielle Bonheur "Coco" Chanel, estilista francesa. 1883-1971. Disponível em: 〈http://www. fashionencyclopedia.com/Ch-Da/Chanel-Gabrielle-Coco.html». Acesso em 14 Mar. 2011. 
noções de beleza e de moda em sua época. Chanel teve oito ambientes ocupados por suas criações e citações, enquanto que Kawakubo ocupou o meio do espaço, com seis monitores que exibiam imagens de seu último desfile.

Rei Kawakubo também teve seu trabalho apresentado na exposição Radical Fashion, realizada no Victoria and Albert Museum, entre 18 de outubro de 2001 e 6 de janeiro de 2002. Onze estilistas' contemporâneos, mundialmente conhecidos, foram convidados a criar instalações para a exposição. Segundo Claire Wilcox (2001), curadora da exposição, esses designers foram motivados por diferentes impulsos e são de diferentes gerações. Eles têm em comum uma visão da moda que foge àquela estabelecida: desafiando ideias convencionais, eles se comprometem a buscar formas desafiadoras de beleza, obtendo, assim, diversos e provocativos resultados. Dentro da exposição, a sala dedicada a Rei Kawakubo apresentava peças de suas coleções, projeções de formas geométricas em branco, vermelho e preto sobre o ambiente, além de um vídeo de sua coleção de Primavera/Verão de $2002^{10}$.

A exibição ReFUSING FASHION: Rei Kawakubo, dedicada inteiramente à estilista, procurou apresentar o trabalho de Kawakubo como uma série de intervenções e rupturas na área do design de moda. Para Koda (2008), se seu trabalho é visto como "antimoda no mundo da moda, ou como feio e desajeitado" em um sistema classicamente dedicado ao bom gosto, o trabalho de Kawakubo é um constante processo de renovação do vocabulário e de pensamento. Sua moda inovadora, seus métodos únicos de fabricação e suas colaborações com artistas de diversos campos foram explorados em uma instalação com seus trabalhos no MOCAD, o Museu de Arte Contemporânea de Detroit" ${ }^{11}$. A exposição, que durou de 8 de fevereiro à 20 de abril de 2008, incluía mais de 40

Figura 6 - Imagem criada pela artista Cindy Sherman em colaboração com a Comme des Garçons. Fonte: Comme des Garçons, 2000.
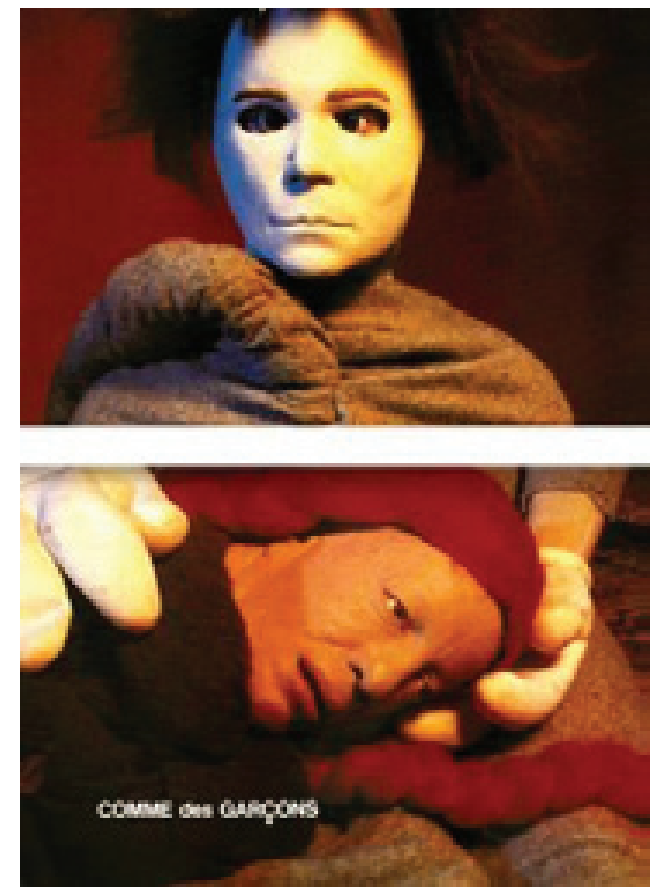

9 Os designers escolhidos foram Azzedine Alaïa, Hussein Chalayan, Comme des Garçons, Helmut Lang, Jean Paul Gaultier, Maison Martin Margiela, Alexander McQueen, Issey Miyake, Junya Watanabe, Vivienne Westwood, Yohji Yamamoto.

10 Informações sobre a exposição coletadas em aula da Profš Cristiane Mesquita, ocorrida na disciplina de Design, Arte e Moda no curso de Mestrado em Design da Universidade Anhembi Morumbi.

11 MOCAD: http://www.mocadetroit.org/exhibitions/comme.html/ . Acesso em 11/04/2011. 


\section{A arte de Rei Kawakubo: diálogos entre moda e arte no universo da Comme des Garçons}

peças-chave, figurinos, fotografias e filmagens de desfiles. A comissão de exposição do museu - um grupo de artistas, historiadores de arte, colecionadores e curadores - adotou uma abordagem artística da organização, vendo a exposição como uma instalação e como uma Gesamtkunstwerk, ou obra de arte total: todas as peças juntas se revelando como um todo.

A Comme des Garçons foi alvo de interesse de diversas outras exposições ao redor do mundo, como a Mode et Photo, uma exibição fotográfica da Comme des Garçons realizada no Centre Georges Pompidou, em Paris, no ano de 1986; a exposição Tree Voices: Franco Albini, Kris Ruhs, Rei Kawakubo, em Paris, 1993; a exibição Essence of Quality da Comme des Garçons Noir no Kyoto Costume Institute e uma exibição denominada Mode and Art na Bélgica, entre outras.

\section{Cindy Sherman e Comme des Garçons}

Em 1994, a Comme des Carçons fez uma parceria com a renomada artista Cindy Sherman. Sherman é uma artista americana nascida em 1954, que se tornou reconhecida principalmente por seus retratos. Através de uma série de trabalhos, ela levantou questões desafiadoras a respeito do papel e da representação da mulher na sociedade, além de questionar a natureza da criação artística.

0 intuito da parceria era realizar uma série de fotografias para a marca, para serem veiculadas como campanha publicitária. Dessa colaboração, resultaram imagens que questionaram as regras convencionais da fotografia de moda. As fotos produzidas pela interpretação da artista sobre as roupas da Comme des Garçons fogem ao padrão estabelecido. Nas fotografias de Sherman, a própria roupa fica em segundo plano. A figura da modelo, tão comum em revistas e anúncios publicitários de moda, não está presente. No lugar dela é possível ver figuras estranhas e perturbadoras de manequins, com rostos exageradamente maquiados e cabelos desarrumados, presentes no trabalho da artista. Glassock (2010) aponta que, as peças da Comme des Garçons são apropriadas e desapropriadas por Cindy Sherman e torna-se difícil dizer se as roupas nesses manequins são usadas como planejado por Rei Kawakubo ou alteradas pela artista. Pode-se falar que essas fotografias são desconcertantes da perspectiva tradicional da moda ao mesmo tempo em que não se encontram deslocadas no contexto da Comme des Garçons. Ainda segundo Classock (2010), Sherman se estabeleceu como uma grande manipuladora e intérprete de ícones de feminilidade propagados pela mídia de massa.

Após conhecer seu trabalho para a Harper's Bazaar, Kawakubo entrou em contato com Sherman e forneceu a ela diversas peças de coleções da Comme des Garçons para serem usadas como a artista preferisse. As imagens resultantes da campanha foram utilizadas como mala-direta da coleção de Outono/Inverno 1994/1995 e também foram exibidas na loja da marca localizada no SoHo. Ainda de acordo com Glassock (2010), Kawakubo e Sherman utilizam seus trabalhos para questionar sobre a maneira como nos apresentamos à sociedade e ambas subvertem as imagens tradicionais a respeito da feminilidade. As fotografias criadas a partir 
dessa colaboração não têm a pretensão de vender produtos, e, sim, de desafiar as expectativas sobre o que a fotografia de moda deveria ser.

\section{Rei Kawakubo e Merce Cunningham}

Merce Cunningham foi o líder e mestre de uma companhia de dança avant-guarde americana até sua morte, em 2009. Durante seus 70 de carreira, foi um importante coreógrafo e um dos grandes bailarinos de seu tempo, sendo seu trabalho marcado pela constante inovação. Cunningham expandiu fronteiras não só na dança, mas também nas artes visuais contemporâneas.

A parceria entre Cunningham e Kawakubo teve origem com a coleção de Primavera/Verão 1997 da designer, chamada de Dress Meets Body, Body Meets Dress and They Are One. Essa coleção teve grande repercussão e marcou a trajetória da marca. Nela, Kawakubo apresentou roupas que distorciam o corpo das modelos, criando volumes a partir de enchimentos localizados em lugares como o quadril, costas e barriga. Dessa forma, a estilista surpreendeu propondo um novo olhar sobre o corpo feminino.

A dança criada a partir dessa colaboração é intitulada Scenario e sua estreia aconteceu em outubro de 1997. A apresentação é composta de três partes pontuadas pela mudança das estampas e cores dos figurinos: no início, as roupas são listradas ou xadrezes nas cores verde e azul; em seguida, são todas pretas e, ao final, todas vermelhas, porém as deformações continuam as mesmas ao longo da apresentação. Para Granata (2009), a forma como as roupas de Kawakubo são ativadas e modificadas pelos movimentos dos dançarinos permite criar novas formas corporais, reforçando a exploração de Cunningham sobre os limites do corpo e aumentando as distorções nas roupas da coleção de 1997 de Rei Kawakubo. 0 figurino do espetáculo possibilita uma nova percepção do dançarino sobre seu próprio corpo e o corpo dos outros. Dessa forma, podemos considerar que a dança complementa o trabalho de Rei Kawakubo, expandindo sua discussão sobre o corpo, tirando a roupa da passarela e colocando-a em movimento.

\section{Considerações Finais}

Pode-se considerar que há uma linha divisória pouco nítida entre a arte e a moda, sendo que ao longo do século XX essas áreas se relacionaram de forma às vezes harmoniosa e outras vezes conflituosa. Mas o resultado dessas interseções foi um entrelaçamento tão forte entre ambas que se tornou difícil fazer uma distinção clara entre elas.

Ao questionar a moda e suas convenções, propondo um olhar crítico a respeito da mesma, Rei Kawakubo coloca suas criações lado a lado com a arte. De acordo com Svendsen (2010), a moda sempre se situou entre a arte e o capital, abraçando mui- 
tas vezes o lado cultural para abrandar o lado financeiro. Nesse contexto, podemos considerar a criadora como um bom exemplo dos diálogos entre arte e moda, pois a Comme des Carçons é, apesar de toda a sua estética de vanguarda, um negócio que movimenta mais de US\$100 milhões por ano.

A partir das colaborações realizadas pela Comme des Garçons, é possível constatar que elas têm uma grande importância na afirmação da marca como um expoente criativo. Parcerias realizadas com artistas de diferentes áreas enriquecem seu trabalho, pois criam um olhar ampliado sobre a moda de Rei Kawakubo, dando à roupa novos significados. Arte e moda se inter-relacionam e se confundem, discutindo e modificando o contexto cultural em que estão inseridas, criando novas perspectivas e possibilidades de criação. 
A arte de Rei Kawakubo: diálogos entre moda e arte no universo da Comme des Garçons

\section{Referências Bibliográficas}

> CELANT, Germano (Ed.). Art/Fashion. New York: Skira, 1997.

$>$ CRANE, Diana. The Transformation of the Avant-Garde: the New York Art world 1940-1985, Chicago: University of Chicago Press, 1987.

> Dover Street Market. Disponivel em «http://www.doverstreetmarket.com/ about/>. Acesso em 20 Fev. 2011

> Fashion Encyclopedia. Disponível em: «http://www.fashionencyclopedia.com/〉. Acesso em: 17 fev. 2011.

> FUKAl, Akiko et. al. Fashion: A history from the 18th to the 2oth century. Taschen, 2006.

> GLASSOCK, Jessica. Bridging the Art/Commerce Divide: Cindy Sherman and Rei Kawakubo of Commes des Garcons. Disponivel em: <http://www.nyu.edu/greyart/ exhibits/odysseys/Commerce/body_commerce.html> Acesso em 19 Jan. 2011.

> GRANATA, Francesca. Merce Cunningham and Fashion. Disponivel em: «http:// www.fashionprojects.org/?p=605). Acesso em 20 Jan. 2011.

> GRAND, France. Comme des Garçons. São Paulo: Cosac ą Naify Edições, 2000.

$>$ KODA, Harold et. al. ReFusing Fashion: Rei Kawakubo. Museum of Contemporary Art Detroit, 2008

> Le Corbusier: architect biography. Disponível em <http://architect.architecture. sk/le-corbusier-architect/le-corbusier-architect.php> Acesso em: 14 Mar. 2011.

> Museum of Contemporary Art Detroit. Disponível em: <http://www.mocadetroit. org/exhibitions/comme.html/>. Acesso em 14 Mar. 2011.

$>$ PRECIOSA, Rosane. Produção estética: notas sobre roupas, sujeitos e modos de vida. São Paulo: Anhembi Morumbi, 2005.

> SABINO, Marco. Dicionário da Moda. Rio de Janeiro: Editora Elsevier, 2007.

> SUDIIC, Deyan. Rei Kawakubo and Comme des Garçons. Rizzoli International Publications, 1990.

> SVENDSEN, Lars. Moda: uma filosofia. Rio de Janeiro: Zahar, 2010.

> Vionnet. Disponível em: 〈http://www.vionnet.com/about/madeleine-vionnet〉. Acesso em: 17 fev. 2011.

> WILCOX, Claire (Ed.). Radical Fashion. [London]: VCAA Publications, 2001. 
A arte de Rei Kawakubo: diálogos entre moda e arte no universo da Comme des Garçons

Isadora Ferraz Rodrigues, graduanda em Design de Moda pela Universidade Anhembi Morumbi/SP.

fr_isa@hotmail.com

Cristiane Ferreira Mesquita, mestre e doutora em Psicologia pelo Núcleo de estudos e pesquisas da subjetividade (PUC/SP). Professora e pesquisadora do Programa de Pós-Graduação em Design da Universidade Anhembi Morumbi/SP. Seus temas de pesquisa incluem interações entre design, corpo, subjetividade, processos de criação e arte contemporânea.

cfmesquita@anhembi.br 